\title{
Analysis of results of long-term monitoring prestressed anchors In Slope Engineering
}

\author{
Jian $\mathrm{Li}^{1}$, a , Lijie $\mathrm{Li}^{2}$, b \\ ${ }^{1}$ Railway Engineering Research Institute, China Academy of Railway Sciences, Beijing 100081, \\ China \\ ${ }^{2}$ State Key Laboratory of Railway Traffic Control \& Safety, School of Traffic Transportation, \\ Beijing Jiaotong University, Beijing 100044, China \\ a517158105@qq.com, byajiemodeai@163.com
}

Keywords: slope, anchorage cable, prestress, monitoring

\begin{abstract}
Prestressed reinforcement technology has been widely used in Slope Engineering, but anchor prestress losses still lack a comprehensive systematic understanding. Through systematic monitoring and data analysis of prestressed anchors in the slope of a sandy slate, discussion on the Slope Prestress Loss of Cable variation and influencing factors, the main factors pointed sandy slate formation Cable loss is long term stress relaxation strand, resulting in the loss of the traditional anchor long-term stress reached (about 5\%).
\end{abstract}

\section{Introduction}

With the development of modern engineering construction, Slope encountered more and more, while stress Anchor Technology is becoming an important means of reinforcement method has been applied in a lot of slope reinforcement, and has become an effective means. At the same time, during the construction and use of the process for reinforcing the slope, prestressed anchor prestress loss will inevitably occur, there are many references have been studied and discussed that an essential factor in effective prestressed anchor size is also related to the success of the project Consolidation [1, 2, 3, 4]. By 16 months of systematic monitoring of prestressed anchors change a slope, the anchor cable prestress changes were analyzed.

\section{Project Overview}

The work site is mainly composed of Quaternary stratigraphy Qel and sandy slate. Qel brown red gravel soil, thickness of $3.0 \sim 5.0 \mathrm{~m}$; sandy slate was strongly weathered state, tan, fissures, among which there are muddy filling. The landslide slip zone is at fault movement with position, the landslide has been sliding, prestressed anchor cable frame strengthening. The selected test point Pin anchor a frame ( 8 holes) field tests and in-situ monitoring of frame length $6.5 \mathrm{~m}$, high $12 \mathrm{~m}$, by two vertical ribs and four beams composition, slope ratio of 1: 0.5 . Cable length $18 \sim 22 \mathrm{~m}$, horizontal spacing $3.5 \mathrm{~m}$, vertical spacing $3.35 \mathrm{~m}$, each anchor hole produced by the four strands of $\Phi 15.24 \mathrm{~mm}$.

This project uses stress monitoring method, install anchor bolt dynamometer in head position before the cable lock, and get cable tension changes through the anchor dynamometer or regularly monitoring the implementation.

\section{Prestress Loss of Cable Distribution}

Cable prestress loss, including: Cable lock instantaneous loss process and the long-term loss after being locked.

Cable locking process prestressed momentary loss occurred a short time, the reason for the return oil in an instant jack, strand inevitably retract to inner slope and drive clips retraction, and ultimately makes the anchor, clip and strand to achieve the card firmly locked object, strand retraction process also reduces the effective prestressed anchor. 
After the anchor lock anchor prestress generally go through three stages [3, 4]. The first stage is the rapid loss of prestressed stage. Prestress variation characteristics of this stage is the anchoring loss rapidly and loss value after locking damage, to the time is about 3 months. Prestress loss is mainly due to slack in the anchor, the anchor concrete creep and scope of rock caused by compression. The second stage is the stage of anchoring prestressed fluctuations. Anchor prestress prestressed characterized by a slight value, frequent fluctuations. The reason for this change may be due to internal stress adjustment and rock anchor, resulting in compression and rebound of the iterative process, resulting in prestressed anchors fluctuate. The third stage is the stage of steady change. The variation characteristics of anchoring prestress change is relatively stable, If the anchor cable corrosion resistance is poor, it is prestressed occur trend decline in severe cases can lead to sudden rupture anchor damage.

\section{Prestressed long-term monitoring results}

By the monitoring data shows that after locking the anchor into the rapid loss of prestressing stage, basically stabilized after five months, at this stage most of the cable prestress loss of $6 \%$ or less, and a maximum of $11.2 \%$, minimum $1.1 \%$, an average of $4.5 \%$; thereafter anchor into the stress smooth change stage, the performance of prestressed continued to increase, indicating that the gradual landslide thrust at work, the average amount of landslide thrust increase was $3.4 \%$, increasing the range of each anchor prestressing between 1.2 to $6.3 \%$.

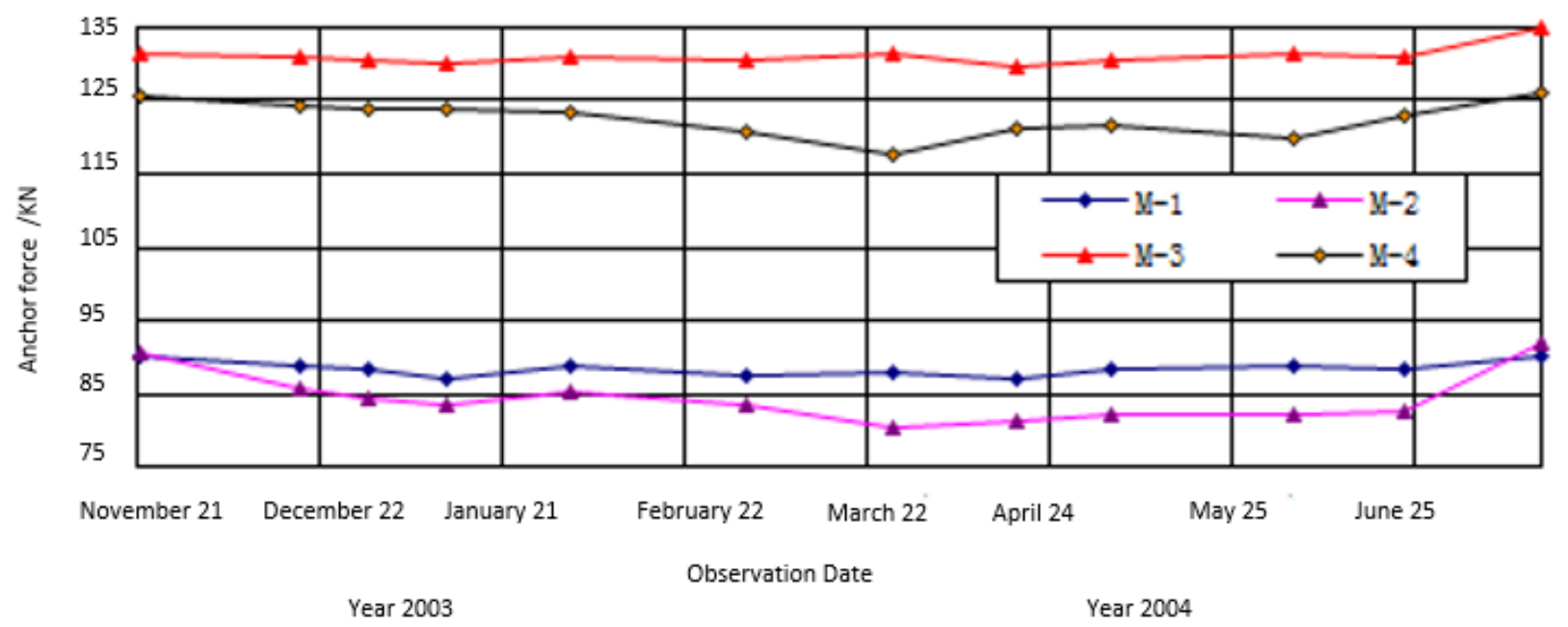

Fig. 1 M-1, M-2, M-3, M-4 cable tension curves in long-term state

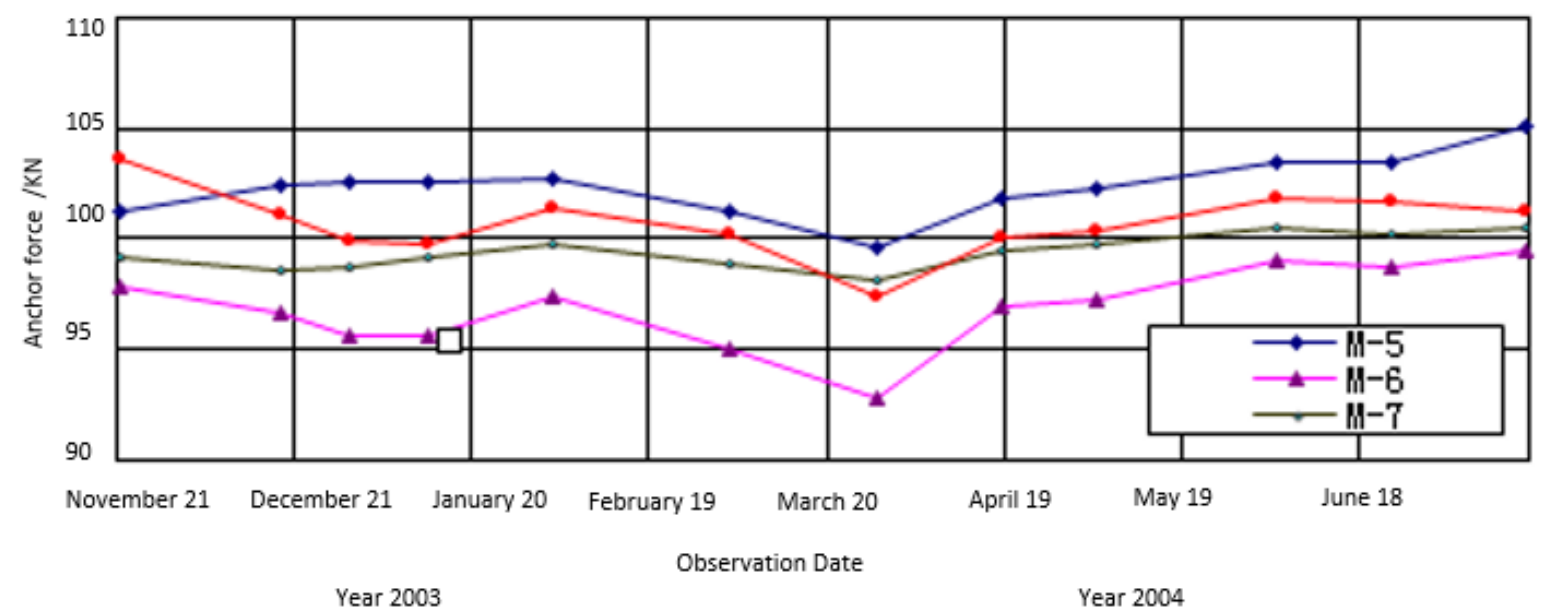

Fig.2 M-5, M-6, M-7, M-8 cable tension curves in long-term state

Stress monitoring results are shown in Table 1.In the 16 months observation period, prestressed continuous decreases, and loss ratio is $15.0 \sim 25.0 \%$. 
Table 1 Anchor cable stress monitoring results summary

\begin{tabular}{cccccc}
\hline Serial number & $\begin{array}{c}\text { Locking value }(\mathrm{kN}) \\
2013.8\end{array}$ & $\begin{array}{c}\text { Final value }(\mathrm{kN}) \\
2014.12\end{array}$ & Loss value (N) & Prestressed loss rate (\%) & $\begin{array}{c}\text { monitoring } \\
\text { cycle }\end{array}$ \\
\hline M-1 & 297.7 & 220.1 & 77.6 & 21.1 & 16 months \\
M-2 & 265.68 & 200.92 & 64.8 & 24.5 & 16 months \\
M-3 & 270.36 & 206.77 & 63.6 & 23.7 & 16 months \\
M-4 & 228.51 & 192.7 & 35.8 & 15.9 & 16 months \\
M-5 & 338.41 & 251.02 & 87.4 & 25.7 & 16 months \\
M-6 & 391.85 & 307.79 & 84.1 & 21.5 & 16 months \\
M-7 & 260.18 & 216.55 & 43.6 & 17.0 & 16 months \\
M-8 & 380.02 & 303.86 & 76.2 & 21.1 & 16 months \\
\hline
\end{tabular}

\section{The main factor of long-term loss of prestressed anchor}

Losses caused by slack strand

Because of the long-term load of prestressed anchor cable, cable body will prestress loss caused by the relaxation.So-called relaxation loss is to point to in the prestressed structure, the body without deformation, as time growth caused by internal prestressed loss.It is the main loss of prestress of prestressed anchor system YingXi one of the factors.Of anchor cable stress relaxation is closely related to the tensile load size, the greater the tension stress, relaxation, the greater the loss when the applied stress is more than $50 \%$ of the strength of steel, the stress relaxation is obvious increase, and increases along with the increase of load, but also affected by the temperature, the higher the temperature, the loss is bigger.Using super tensioning prestressed relaxation loss is significantly affected.Also found that long-term exposure to load steel caused by the creep deformation of prestressed loss, also can make the so-called creep refers to the permanent materials produced by deformation under load, creep, however loss compared with relaxation prestress loss, the loss is negligible.Finally, the relaxation of steel loss related to material properties, related to the material, environmental temperature directly. Table 2 shows the common strand relaxation rate.

Table 2 common strand relaxation rate

\begin{tabular}{ccc}
\hline Strand Type & \multicolumn{2}{c}{ 1000h Allows maximal relaxation rate } \\
\cline { 2 - 3 } & $70 \%$ Maximum load & $80 \%$ Maximum load \\
\hline ASTM416, 270level, $\varphi 15.2$ & 2.5 & 3.5 \\
GB5224, $\varphi 15.24$ & 2.5 & 4.5 \\
Normal slack strand & 8.0 & 12.5 \\
\hline
\end{tabular}

Rock and soil loss caused by creep

Since the rock itself discontinuities and presence of anisotropy, rock by the internal structure of each constituent unit area charge strain under the force plastically compressed or relative displacement, the displacement varies with time this is rock creep. For stress, creep occurs mainly in the area of stress concentration. However, different rock properties, different values of the prestressing loss by the creep. For hard rock, creep is relatively small, and the prestressing loss value is very small, even in large tonnage prestressed load as well.

In addition, different prestress levels have a greater influence on creep, which in turn affect the value of the prestressing loss. Generally, under large tonnage prestressed conditions, creep caused by prestressing loss is relatively small.

Losses caused by the shrinkage and creep of concrete

Anchor head is fixed to the pile, and the frame beam anchor pad pier generally, these structures made of concrete brick, and itself has a contraction, creep properties, and are subject to large tonnage pressure will produce a certain amount of compression deformation, thereby causing loss of prestress.

Cable structure loss due to corrosion

Cable structure during use in multiple external and internal factors, will inevitably be different degrees of corrosion. Strand stress corrosion can cause reduced, or even fracture. 
Anchor cable stress monitoring data show that the sand shale formation, SLATE formation long-term loss of prestress of anchor cable in the smaller, basic in $3 \sim 6 \%$; And coal measures strata, high liquid limit soil slope is high, $15 \sim 25 \%$.Reference other worksite monitoring data, the granite formation, limestone formation such as long-term loss of prestress of anchor cable is not high also, 2 $\sim 5 \%$ in more.Monitoring data show that the coal measures strata, the application of the traditional high liquid limit soil slope anchor cable, because of its poor corrosion resistance, long-term prestress loss is bigger, should be careful when you are using it.

\section{Conclusion}

Combined with a sandy slate SLOPE long-term monitoring data, summarize anchor long-term stress loss factors and rules stated sandy slate formation anchor long term stress losses of up to (around 5\%), the main factor is the strand shrinkage and creep, relaxation anchor structure, rock and soil creep, corrosion of concrete. It has some theoretical significance for prestressed anchor and engineering.

\section{References}

[1] SU Xuegui, LI Yanbi, MENG Xiusheng. Analysis of the factors affecting prestress-losing inprestressed cable anchor[J]. Journal of Xi'an Mining Institu, 19, 19(Supp.): 87-90. (in Chinese)

[2] ZHANGFamin, LIU Nin, CHEN Zu, et al. Analysis of factors affectingload losses of high capacity and long rock anchors[J]. Rock and SoilMechanics, 2003 24(2): 194-197. (in Chinese)

[3] ZHU Han, SUN Hongy, WANG Huiba, et al. Analysis of prestress state of cable applied to rock slope reinforcement[J]. Chinese Journal of Rock Mechanics and Engineeri, 20, 23(16): 2 756-2 760. (in Chinese)

[4] ZHANG Fami, ZHAO Weibi, LIU Ni, et al. Long-term performance and load prediction model of prestressed cables[J]. Chinese Journal of Rock Mechanics and Engineeri, 20, 23(1): 39-43. (in Chinese) 